\title{
Clinicopathological Characteristics of Triple-negative Breast Cancers in the Northeast Region of Turkey
}

\author{
Bülent Yıldız ${ }^{1}$, Evren Fidan², Feyyaz Özdemir ${ }^{3}$, Orhan Sezen ${ }^{4}$, Halil Kavgaci ${ }^{3}$, Fazıl Aydın \\ ${ }^{1}$ Department of Medical Oncology, Eskişehir Osmangazi University Faculty of Medicine, Eskişehir, Turkey \\ ${ }^{2}$ Department of Medical Oncology, Konya Training and Research Hospital, Konya, Turkey \\ ${ }^{3}$ Department of Medical Oncology, Karadeniz Technical University Faculty of Medicine, Trabzon, Turkey \\ ${ }^{4}$ Department of Radiation Oncology, Karadeniz Technical University Faculty of Medicine, Trabzon, Turkey
}

Background: Triple-negative (TN) breast cancer is a subtype of breast cancer characterised by a loss of estrogen receptor (ER), progesterone receptor (PR) expression, and the absence of human epidermal growth factor (HER2) overexpression.

Aims: To identify the relationships between clinicopathological characteristics of TN breast cancers in the northeast region of Turkey and disease free survival (DFS) and overall survival (OS).

Study Design: Retrospective clinical study.

Methods: Seven hundred and eighty non-metastatic breast cancer patients were enrolled in this study. The relationships between $\mathrm{TN}$ breast cancer and other breast cancers with respect to clinicopathological characteristics, as well as DFS and OS, were studied.

Results: The triple-negative phenotype was detected in 204 patients $(27.1 \%)$. Patients with triple-negative breast cancer had more grade 2-3 tumours compared to those with other types of breast cancer ( $92.5 \%$ versus $84.3 \%, \mathrm{p}=0.004)$. Invasive ductal carcinoma histology, on the other hand, was less prevalent in patients with TN breast cancer
(77\% versus $84.5 \%, \mathrm{p}=0.016)$. No significant differences were identified between the groups in other clinicopathological variables. Relapse and mortality rates were higher in the TN group during the follow-up of both groups [57 (27.9\%) versus $89(16.2 \%), \mathrm{p}<0.001$ for relapse; $27(13.2 \%)$ versus $37(6.8 \%), p=0.005$ for mortality]. The univariate analysis demonstrated shorter DFS and OS for patients with TN breast cancer compared to those with other types of breast cancer. In the multivariate analysis, patients with $\mathrm{TN}$ breast cancer were 2.21 times more likely to develop relapse, while the likelihood of death increased 3.21fold $(\mathrm{p}<0.001$ and $\mathrm{p}<0.001)$.

Conclusion: Triple-negative breast cancers demonstrate a more aggressive clinical course compared to other breast cancers. More effective strategies should be developed for the treatment of this subgroup of breast cancer.

(Balkan Med J 2014;31:126-31).

Key Words: Breast neoplasms, disease free survival, overall survival
Breast cancer is the most common malignancy among women and a leading cause of cancer-related deaths in the general population. On the other hand, both incidence and mortality rates decreased over the past $10-15$ years (1). Different clinical courses observed in cancer patients during the same stage suggest that this disease has a heterogeneous nature.

Breast cancer has been categorised into 5 subtypes based on gene expression techniques (luminal A, luminal B, basal-like, human epidermal growth factor (HER2)-overexpressing, and normal breast like) (2-5). Estrogen receptor (ER), progesterone receptor (PR), and HER2 receptors are negative in basallike tumours, as in the case of triple-negative (TN) tumours. Because anti-keratin antibodies, used to identify the basal-like phenotype, are not routinely analysed during daily practice, the terms TN and basal-like are often used interchangeably. This, however, is not precisely accurate. DNA analyses and immunohistochemical assays have demonstrated that $85 \%$ of TN tumours were basal-like. Basal-like tumours have a shorter disease free survival (DFS) and poorer prognosis and are associated with BRCA-1 $(2,4,5)$. The clinical behaviour of TN tumours is also similar to basal-like tumours and these tumours both have poor prognosis (4-7).

Triple-negative tumours account for 10.6-29.5\% of all breast cancers (8-12). As proven by the results of previous studies, standard treatment protocols used for breast cancer management have not yielded the expected successful results in this subgroup to date. Therefore, the accurate identification of clinicopathological characteristics of TN breast cancer, as well as its prognostic and predictive factors, will provide guidance in developing effective treatment strategies for the patients in this subgroup with complicated management. 
The aim of this study is to identify the relationships between clinicopathological characteristics of TN breast cancers and DFS and overall survival (OS) in the northeast region of Turkey.

\section{MATERIAL AND METHODS}

\section{Patients}

Nine hundred and sixteen patients with diagnosed breast cancer presenting to the Karadeniz Technical University Faculty of Medicine Medical Oncology out-patient' clinic between January 2003 and December 2008 were scheduled to enroll in the study. However, 136 patients were excluded since they were at the metastatic stage at the time of diagnosis or were lost to follow-up; therefore, 780 patients were included in the study. The present retrospective study was approved by the Institutional Ethics Committee.

The patients were invited to the clinic at three-month intervals during the first two years following adjuvant treatment, in six-month intervals during the next two years, and then annually. During each visit, physical examinations were carried out and the patients were asked to undergo blood analyses (complete blood count, routine biochemical tests, and tumour markers), annual mammography and/or breast USG, annual abdominal USG or BT and additional examinations including bone profile and bone scintigraphy, if indicated; all of the patients were monitored for relapse/metastasis.

In this study, ER-, PR- and HER2- negative patients were considered to have TN breast cancer, while patients who were positive for any of these markers were defined as "other breast cancers". Breast cancer stage at diagnosis was defined by the American Joint Committee on Cancer Staging Manual 6th edition (13). Modified Black's nuclear grading system was used for nuclear grading of pathology preparations (14).

Disease free survival was described as the period (months) from the time of patient's diagnosis until determining a local relapse or metastasis. Overall survival was defined as the period (months) from the time of the patient's diagnosis until the last visit or death.

\section{Immunohistochemical (IHC) staining}

Immunohistochemical (IHC) staining was performed using an automated staining system (Nexes IHC, Ventana $(15,16)$. ER (Clon SP1; NeoMarkers, California, USA), PR (Clon SP2, NeoMarkers, California, USA), and HER2 (Clon e2-4001+3B5, NeoMarkers, California, USA) were used as the primary antibodies. For ER and PR, $>10 \%$ nuclear staining of cells was considered positive expression $(17,18)$. For HER2, grades from 0 to +3 were given based on the degree of membranous staining; staining with grades 0 to +1 were deemed negative, grade +2 staining was considered borderline, and grade +3 staining was considered positive. Patients displaying grade +2 staining pattern underwent FISH and those with HER2 gene $<2$ copies were considered negative $(7,8)$.

\section{Statistical analysis}

Statistical evaluations were performed on computers using the SPSS 13 (SPSS Inc., Chicago, IL, USA) (License no: 31133001) sta- tistics software. Chi-square test was used for comparisons between TN and non-TN groups for relationships with respect to clinicopathological characteristics (diameter, lymph node involvement, presence of menopause, histological type, etc.), while comparisons of means (age and tumour diameter) were carried out using the Student's $t$ test. Relationships between the variables to DFS and OS were assessed by the Kaplan-Meier survival analysis. For the variables which were statistically significant in univariate analysis, multivariate Cox regression analysis was used. The level of significance was established as $\mathrm{p}<0.05$.

\section{RESULTS}

Of the 780 patients enrolled, $752(96.4 \%)$ had receptors for all three hormones (ER, PR and HER2), while at least one receptor was unknown in 28 patients (3.6\%). TN phenotype was detected in 204 patients (27.1\%). The median follow-up was 36 months (range, 5-77 months).

Clinicopathological characteristics of 752 patients with known hormone receptor status are shown in Table 1. No statistically significant relationships were identified between TN and non-TN breast cancer groups in terms of the studied parameters, which included mean age at the time of diagnosis, tumour diameter, lymph node involvement, disease stage, lymphovascular invasion, and the presence of menopause. Moderately and poorly differentiated tumours were more common in patients with TN breast cancer compared to patients with other breast cancers $(92.5 \%$ versus $84.3 \%, \mathrm{p}=0.004)$. Invasive ductal carcinoma histology was less common in patients with $\mathrm{TN}$ breast cancer $(77 \%$ versus $84.5 \%, \mathrm{p}=0.016)$. On the other hand, both relapse and mortality was noted with a higher rate in the TN group during the follow-up period [57 (27.9\%) versus $89(16.2 \%), p<0.001$ for relapse; $27(13.2 \%)$ versus 37 (6.8\%), $\mathrm{p}=0.005$ for mortality].

The impact of the studied variables on DFS and OS, as demonstrated by the univariate analysis, is presented in Table 2. Patients with TN breast cancer had shorter DFS and OS compared to patients with other breast cancers (57.1 months versus 63.8 months, $\mathrm{p}=0.004$ for DFS and 66.8 months versus 71.2 months, $p=0.024$ for OS) (Figure 1a, b). Results of the multivariate analysis carried out for variables with $p$ values lower than 0.05 in the univariate analysis are shown in Table 3 . The patients with $\mathrm{TN}$ breast cancer were 2.21 times more likely to develop relapse, while the likelihood of death was increased 3.21-fold $(p<0.001$ and $p<0.001)$.

\section{DISCUSSION}

Breast cancer is a heterogeneous disease. Survival may differ even among individuals with similar prognostic factors and in the same disease stage. Treatment strategies for the 
TABLE 1. Characteristics of patients with triple negative and other breast cancer groups

\begin{tabular}{|c|c|c|c|}
\hline Variable & $\begin{array}{c}\text { Other (n:548) } \\
\mathrm{n}(\%)\end{array}$ & $\begin{array}{c}\mathrm{TN}(\mathrm{n}: 204) \\
\mathrm{n}(\%)\end{array}$ & $\mathrm{p}$ \\
\hline Mean age at diagnosis (y) & 52.01 & 51.23 & 0.448 \\
\hline$<35$ years & $33(6)$ & $14(6.9)$ & \\
\hline$\geq 35$ years & $515(94)$ & $190(93.1)$ & 0.672 \\
\hline Mean tumour size & 3.72 & 3.70 & 0.922 \\
\hline$\leq 5 \mathrm{~cm}$ & $458(83.7)$ & $165(80.9)$ & \\
\hline$>5 \mathrm{~cm}$ & $89(16.3)$ & $39(19.1)$ & \\
\hline Missing & 1 & 0 & 0.356 \\
\hline \multicolumn{4}{|l|}{ Lymph node status } \\
\hline Negative & $200(37.5)$ & $86(43)$ & \\
\hline Positive & $333(62.5)$ & $114(57)$ & \\
\hline Missing & 15 & 4 & 0.176 \\
\hline \multicolumn{4}{|l|}{ Stage } \\
\hline Early stage (I-II) & $330(62)$ & $130(65.3)$ & \\
\hline Locally advanced (III) & $202(38)$ & $69(34.7)$ & \\
\hline Missing & 16 & 5 & 0.411 \\
\hline \multicolumn{4}{|l|}{ Tumour grade } \\
\hline I & $77(15.7)$ & $13(7.5)$ & \\
\hline II-III & $415(84.3)$ & $160(92.5)$ & \\
\hline Missing & 56 & 31 & 0.004 \\
\hline \multicolumn{4}{|l|}{ Lymphovascular invasion } \\
\hline Negative & $47(19.2)$ & $11(12.8)$ & \\
\hline Positive & $198(80.8)$ & $75(87.2)$ & \\
\hline Missing & 303 & 118 & 0.180 \\
\hline \multicolumn{4}{|l|}{ Localisation } \\
\hline Right & $268(48.9)$ & $90(44.1)$ & \\
\hline Left & $280(51.1)$ & $114(55.9)$ & 0.242 \\
\hline \multicolumn{4}{|l|}{ Histological type } \\
\hline Ductal & $463(84.5)$ & $157(77)$ & \\
\hline Non-ductal & $85(15.5)$ & $47(23)$ & $0.016^{*}$ \\
\hline \multicolumn{4}{|l|}{ Menopause status } \\
\hline Pre-menopause & $274(50.3)$ & $107(52.5)$ & \\
\hline Post-menopause & $271(49.7)$ & $97(47.5)$ & \\
\hline Men & 3 & 0 & 0.596 \\
\hline \multicolumn{4}{|l|}{ Nux } \\
\hline Absent & $459(83.8)$ & $147(72.1)$ & \\
\hline Present & $89(16.2)$ & $57(27.9)$ & $<0.001^{\star}$ \\
\hline \multicolumn{4}{|l|}{ Ex } \\
\hline Absent & $511(93.2)$ & $177(86.8)$ & \\
\hline Present & $37(6.8)$ & $27(13.2)$ & $0.005^{x}$ \\
\hline \multicolumn{4}{|l|}{ Adjuvant chemotherapy } \\
\hline Yes & $476(88.8)$ & $195(96.1)$ & \\
\hline No & $60(11.2)$ & $8(3.9)$ & \\
\hline Unknown & 12 & 1 & $0.002^{*}$ \\
\hline \multicolumn{4}{|l|}{ Adjuvant radiotherapy } \\
\hline Yes & $304(56.9)$ & $104(51.5)$ & \\
\hline No & $230(43.1)$ & $98(48.5)$ & \\
\hline Unknown & 14 & 2 & 0.185 \\
\hline \multicolumn{4}{|l|}{ Adjuvant hormonotherapy } \\
\hline Yes & $460(86)$ & $11(5.4)$ & \\
\hline No & $75(14)$ & $192(94.6)$ & \\
\hline Unknown & 13 & 1 & $<0.001^{\times}$ \\
\hline
\end{tabular}

Statistically significant

TN: triple-negative
non-TN population include chemotherapy, hormonotherapy, and HER2-targeted treatments (trastuzumab), whereas patients with TN breast cancer may only use the chemotherapy option among these agents. Better insight and more effective treatment choices are required for this subgroup with a disease that has an aggressive course and limited treatment strategies. However, clinical data on TN breast cancers are very limited in Turkey. No relevant studies have been conducted so far in the Northeast region of Turkey, where the present study was carried out.

Triple-negative tumours were identified at a rate of $27.1 \%$ in our study, which is at the upper limit compared to the data from previous studies and may be explained by ethnic and geographical differences. In a study by Lund et al. (12), in three different states of the United States, the frequency of TN was $46.6 \%$ in African Americans and $21.8 \%$ in Caucasians. However, there is no standard cut-off value for ER, PR, and HER2 receptor positivity among studies on TN breast cancer. While some studies adopt $>10 \%$ staining as positivity criterion for ER and PR $(6,17-21)$, others use a limit of $>5 \%$ $(7,8)$, and some others accept any degree of staining as positive $(12,22)$. Similarly, +3 staining is accepted as positive for HER 2 in some studies $(8,19)$, while others use $\geq+2$ staining and positivity criterion $(12,21)$. In two studies carried in the same city, Aksoy et al. (8) identified the TN prevalence to be $10.6 \%$, whereas the prevalence reported by Mersin et al. (11) was $24.8 \%$. These data indicate that it is likely to obtain diverse prevalence values for $\mathrm{TN}$ in patients with breast cancer residing in the same geographical region, if different cut-off values are adopted for immunohistochemical staining.

In the present study, tumour grade was found to be higher in $\mathrm{TN}$ breast cancer compared to the non-TN group, which is consistent with several previous studies $(6,8,19-21)$. On the other hand, no statistically significant difference was noted between $\mathrm{TN}$ and other breast cancers in other parameters including age, tumour diameter, lymph node involvement, stage, and menopausal state. Although there were no differences in terms of lymphovascular invasion, these data were unknown in the majority of subjects of the current study (421 subjects). Previous studies have reported larger tumour diameters $(6,17,21-23)$ and more cases of lymph node metastases (17) and younger ages of diagnosis $(7,8,19,20,23)$ in $\mathrm{TN}$ breast cancer compared to other breast cancers. On the other hand, some other studies have identified no significant differences between $\mathrm{TN}$ tumours and other breast cancers with regard to age $(11,22)$, diameter $(8,11,20)$, and lymph node involvement $(6,11,20,21)$, consistent with the present study. Although lymph node metastases presented no statistical significance in the present study, it was more common in the TN group. However, higher occurrences of both relapse and death in the TN group indicate that $\mathrm{TN}$ cancers favour metastases in a hematogenous pattern. In a study by Zhang et al. (23), DFS 
TABLE 2. Association between variables and survival in univariate analysis

\begin{tabular}{|c|c|c|c|c|c|c|}
\hline \multirow[b]{2}{*}{ Variables } & \multicolumn{3}{|c|}{ DFS } & \multicolumn{3}{|c|}{ OS } \\
\hline & OR & $(\% 95 \mathrm{CI})$ & $\mathrm{p}$ & OR & $(\% 95 \mathrm{CI})$ & $\mathrm{p}$ \\
\hline \multicolumn{7}{|l|}{$\mathrm{TN}$} \\
\hline (presence vs. absence) & 1.61 & $(1.16-2.25)$ & $0.004^{x}$ & 1.76 & $(1.07-2.89)$ & $0.024^{x}$ \\
\hline \multicolumn{7}{|l|}{ Age } \\
\hline$(<35$ vs. $\geq 35 \mathrm{y})$ & 0.76 & $(0.42-1.37)$ & 0.351 & 1.56 & $(0.49-4.95)$ & 0.450 \\
\hline \multicolumn{7}{|l|}{ Tumour size } \\
\hline$(\leq 5 \mathrm{~cm}$ vs. $>5 \mathrm{~cm})$ & 1.99 & $(1.39-2.84)$ & $<.001^{\mathrm{x}}$ & 1.87 & $(1.11-3.15)$ & 0.017 \\
\hline \multicolumn{7}{|l|}{ Lymph node status } \\
\hline (positive vs. negative) & 3.12 & $(2.06-4.73)$ & $<.001^{\times}$ & 3.37 & $(1.72-6.63)$ & $<0.001^{\mathrm{x}}$ \\
\hline \multicolumn{7}{|l|}{ Stage } \\
\hline (stage I-II vs. III) & 4.08 & $(2.89-5.74)$ & $<.001^{x}$ & 3.38 & $(2.00-5.70)$ & $<0.001^{\mathrm{x}}$ \\
\hline \multicolumn{7}{|l|}{ Tumour grade } \\
\hline (I vs. II-III) & 1.96 & $(1.09-3.55)$ & 0.023 & 2.37 & $(0.95-5.91)$ & 0.057 \\
\hline \multicolumn{7}{|l|}{ Lymphovascular invasion } \\
\hline (negative vs. positive) & 1.82 & $(0.87-3.78)$ & 0.105 & 1.18 & $(0.41-3.37)$ & 0.760 \\
\hline \multicolumn{7}{|l|}{ Localisation } \\
\hline (right vs. left) & 0.95 & $(0.69-1.31)$ & 0.753 & 0.86 & $(0.53-1.38)$ & 0.521 \\
\hline \multicolumn{7}{|l|}{ Histological type } \\
\hline (ductal vs. non-ductal) & 1.56 & $(0.97-2.49)$ & 0.063 & 1.49 & $(0.74-3.00)$ & 0.265 \\
\hline \multicolumn{7}{|l|}{ Menopause status } \\
\hline (pre-menopause vs. post-menopause) & 0.87 & $(0.63-1.19)$ & 0.378 & 1.09 & $(0.68-1.75)$ & 0.714 \\
\hline \multicolumn{7}{|l|}{ Chemotherapy } \\
\hline (yes vs. no) & 2.59 & $(1.14-5.85)$ & $0.018^{x}$ & 1.48 & $(0.54-4.07)$ & 0.445 \\
\hline \multicolumn{7}{|l|}{ Radiotherapy } \\
\hline (yes vs. no) & 2.73 & $(1.88-3.95)$ & $<.001^{\mathrm{x}}$ & 2.74 & $(1.57-4.80)$ & $<0.001^{\mathrm{x}}$ \\
\hline \multicolumn{7}{|l|}{ Hormonotherapy } \\
\hline (yes vs. no) & 0.48 & $(0.34-0.66)$ & $<.001^{\times}$ & 0.53 & $(0.32-0.87)$ & $0.010^{*}$ \\
\hline \multicolumn{7}{|l|}{ ER } \\
\hline (positive vs. negative) & 0.46 & $(0.33-0.64)$ & $<.001^{\times}$ & 0.46 & $(0.27-0.77)$ & $0.003^{\mathrm{x}}$ \\
\hline \multicolumn{7}{|l|}{ PR } \\
\hline (positive vs. negative) & 0.58 & $(0.41-0.80)$ & $0.001^{\times}$ & 0.51 & $(0.30-0.85)$ & $0.008^{x}$ \\
\hline \multicolumn{7}{|l|}{ HER2 } \\
\hline (positive vs. negative) & 1.80 & $(1.23-2.64)$ & $0.002^{x}$ & 2.15 & $(1.25-3.70)$ & $0.005^{*}$ \\
\hline
\end{tabular}

'Statistically significant

OR: odds ratio; TN: triple-negative; ER: estrogen receptor; PR: progesterone receptor; HER2: human epidermal growth factor; DFS: disease free survival; OS: overall survival

TABLE 3. The effects of variables on disease-free survival and overall survival in multivariate analysis

\begin{tabular}{|c|c|c|c|c|c|c|}
\hline \multirow[b]{2}{*}{ Variables } & \multicolumn{3}{|c|}{ Disease free survival } & \multicolumn{3}{|c|}{ Overall survival } \\
\hline & $\mathrm{RR}$ & $(95 \% \mathrm{CI})$ & $\mathrm{p}$ & $\mathrm{RR}$ & $(95 \% \mathrm{CI})$ & $\mathrm{p}$ \\
\hline $\mathrm{TN}$ & 2.21 & $(1.48-3.29)$ & $<0.001^{x}$ & 3.21 & $(1.68-6.10)$ & $<0.001^{*}$ \\
\hline Tumour size & 1.60 & $(1.07-2.40)$ & $0.022^{x}$ & 1.34 & $(0.72-2.49)$ & 0.350 \\
\hline Lymph node status & 2.46 & $(1.59-3.83)$ & $<0.001^{x}$ & 2.35 & $(1.17-4.73)$ & 0.016 \\
\hline Tumour grade & 1.55 & $(0.85-2.83)$ & 0.151 & 1.60 & $(0.63-4.08)$ & 0.320 \\
\hline HER2 & 2.60 & $(1.66-4.09)$ & $<0.001^{\times}$ & 3.46 & $(1.69-7.11)$ & $<0.001^{\times}$ \\
\hline
\end{tabular}

Statistically significant

TN: triple-negative; HER2: human epidermal growth factor; RR: relative risk

and OS was shorter, although lymph node involvement was less common in TN tumours compared to other breast cancers, which is supportive of this hypothesis.

The analyses demonstrated a higher impact of TN tumours on patient survival compared to other tumours. The univariate analysis showed shorter DFS and OS, consistent with the data from previous studies $(7,19-21,24)$. The presence of poor prognostic factors known for breast cancer describes shorter survival relative to other breast cancers. A study by Nishumura et al. (21) confirmed through multivariate analysis that a 


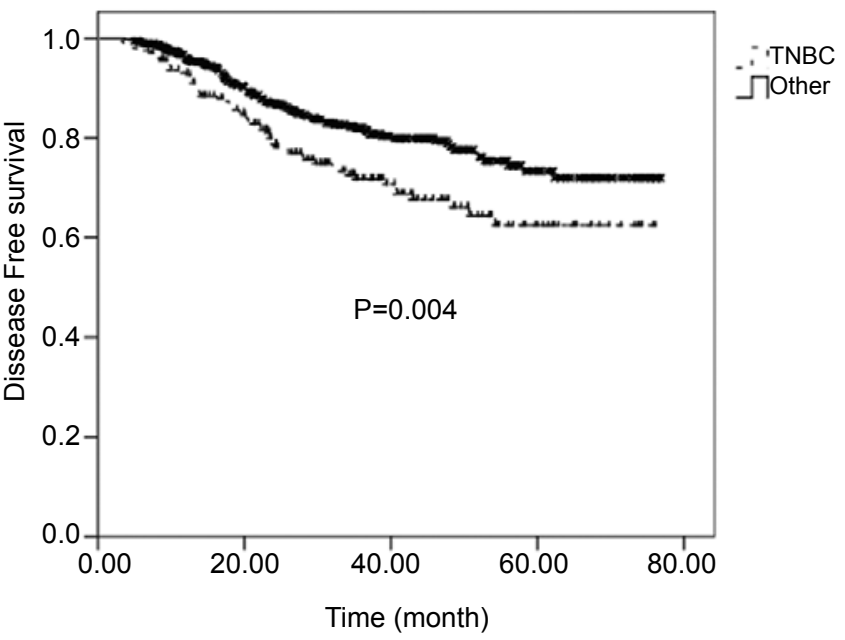

b

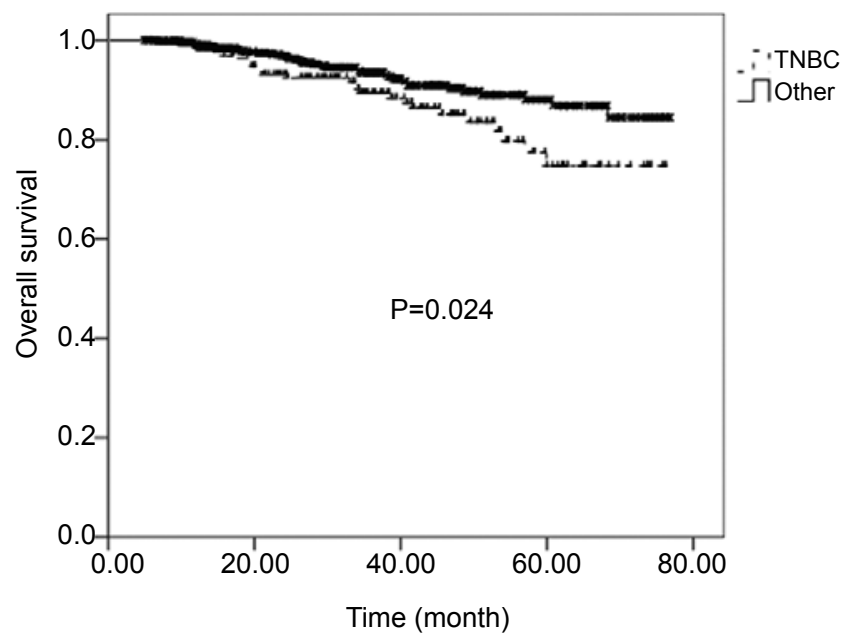

FIG. 1. a, b. Kaplan-Meier curves for disease free survival (a). Kaplan-Meier curves for overall survival (b).

TN tumour was an independent prognostic factor on both DFS and OS. Similarly, TN breast cancer, identified to be an independent prognostic factor, increased the risk of relapse 2.21fold and the risk of death 3.21 -fold in the multivariate analysis of the present study.

In conclusion, $\mathrm{TN}$ breast cancers have a substantial prevalence among breast tumours both in our region and in different geographies. Better insight into clinicopathological characteristics, as well as its prognostic and predictive factors, will provide guidance to clinicians in developing effective treatment strategies for this subgroup with high rates of relapse and mortality.

Ethics Committee Approval: Ethics committee approval was received for this study from local ethics committee (The protocol number: 2009/53; 08.01.2010).

\section{Informed Consent: N/A.}

Peer-review: Externally peer-reviewed.

Author contributions: Concept - H.K.; Design - B.Y.; Supervision - B.Y., O.S.; Resource - B.Y., F.A.; Materials - F.Ö.; Data Collection\&/or Processing - B.Y., E.F.; Analysis\&/or Interpretation - B.Y.; Literature Search - B.Y.; Writing - B.Y.; Critical Reviews - B.Y., E.F.

Conflict of Interest: No conflict of interest was declared by the authors.

Financial Disclosure: The authors declared that this study has received no financial support.

\section{REFERENCES}

1. Jemal A, Bray F, Center MM, Ferlay J, Ward E, Forman D. Cancer statistics. CA Cancer J Clin 2011;61:69-90. [CrossRef]
2. Perou CM, Sørlie T, Eisen MB, van de Rijn M, Jeffrey SS, Rees CA, et al. Molecular portraits of human breast tumours. Nature 2000;406:74752. [CrossRef]

3. Abd El-Rehim DM, Ball G, Pinder SE, Rakha E, Paish C, Robertson JF, et al. High-throughput protein expression analysis using tissue microarray technology of a large well-characterised series identifies biologically distinct classes of breast cancer confirming recent cDNA expression analyses. Int J Cancer 2005;116:340-50. [CrossRef]

4. Sorlie T, Tibshirani R, Parker J, Hastie T, Marron JS, Nobel A, et al. Repeated observation of breast tumor subtypes in independent gene expression data sets. Proc Natl Acad Sci USA 2003;100:8418-23. [CrossRef]

5. Sorlie T, Perou CM, Tibshirani R, Aas T, Geisler S, Johnsen H, et al. Gene expression patterns of breast carcinomas distinguish tumor subclasses with clinical implications. Proc Natl Acad Sci USA 2001;98:10869-74. [CrossRef]

6. Rakha EA, El-Sayed ME, Green AR, Lee AH, Robertson JF, Ellis IO. Prognostic markers in triple-negative breast cancer. Cancer 2007;109:25-32. [CrossRef]

7. Bauer KR, Brown M, Cress RD, Parise CA, Caggiano V. Descriptive analysis of estrogen receptor (ER)-negative, progesterone receptor (PR)-negative, and HER2-negative invasive breast cancer, the so-called triple-negative phenotype: a population-based study from the California cancer registry. Cancer 2007;109:1721-8. [CrossRef]

8. Aksoy S, Dizdar O, Harputluoglu H, Altundag K. Demographic, clinical, and pathological characteristics of Turkish triple-negative breast cancer patients: single center experience. Ann Oncol 2007;18:1904-6. [CrossRef]

9. Suresh P, Batra U, Doval DC. Epidemiological and clinical profile of triple negative breast cancer at a cancer hospital in North India. Indian $J$ Med Paediatr Oncol 2013;34:89-95. [CrossRef]

10. Li CY, Zhang S, Zhang XB, Wang P, Hou GF, Zhang J. Clinicopathological and prognostic characteristics of triple- negative breast cancer (TNBC) in Chinese patients: a retrospective study. Asian Pac J Cancer Prev 2013;14:3779-84. [CrossRef]

11. Mersin H, Yildirim E, Berberoglu U, Gülben K. The prognostic importance of triple negative breast carcinoma. Breast 2008;17:341-6. [CrossRef]

12. Lund MJ, Trivers KF, Porter PL, Coates RJ, Leyland-Jones B, Brawley OW. Race and triple negative threats to breast cancer survival: a population-based study in Atlanta, GA. Breast Cancer Res Treat 2009;113:357-70. [CrossRef] 
13. Greene FL. AJCC cancer staging manual. 6th ed. New York: Springer; 2002. [CrossRef]

14. Fisher B, Redmond C, Fisher ER, Caplan R. Relative worth of estrogen or progesterone receptor and pathologic characteristics of differentiation as indicators of prognosis in node negative breast cancer patients: findings from National Surgical Adjuvant Breast and Bowel Project Protocol B-06. J Clin Oncol 1988;6:1076-87.

15. Kowalski PJ, Rubin MA, Kleer CG. E-cadherin expression in primary carcinomas of the breast and its distant metastases. Breast Cancer Res 2003;5:217-22. [CrossRef]

16. Arun B, Kilic G, Yen C, Foster B, Yardley D, Gaynor R, et al. Correlation Bcl-2 and p53 Expression in Primary Breast Tumors and Corresponding Metastatic Lymph Nodes. Cancer 2003;98;2554-9. [CrossRef]

17. Dent R, Trudeau M, Pritchard KI, Hanna WM, Kahn HK, Sawka CA, et al. Triple-negative breast cancer: clinical features and patterns of recurrence. Clin Cancer Res 2007;13:4429-34. [CrossRef]

18. Kim JE, Ahn HJ, Ahn JH, Yoon DH, Kim SB, Jung KH, et al. Impact of triple-negative breast cancer phenotype on prognosis in patients with stage I breast cancer. J Breast Cancer 2012;15:197-202. [CrossRef]
19. Rhee J, Han SW, Oh DY, Kim JH, Im SA, Han W, et al. The clinicopathologic characteristics and prognostic significance of triple-negativity in node-negative breast cancer. BMC Cancer 2008;8:307. [CrossRef]

20. Liedtke C, Mazouni C, Hess KR, André F, Tordai A, Mejia JA, et al. Response to neoadjuvant therapy and long-term survival in patients with triplenegative breast cancer. J Clin Oncol 2008;26:1275-81. [CrossRef]

21. Nishimura R, Arima N. Is triple negative a prognostic factor in breast cancer? Breast Cancer 2008;15:303-8. [CrossRef]

22. Yin WJ, Lu JS, Di GH, Lin YP, Zhou LH, Liu GY, et al. Clinicopathological features of the triple-negative tumors in Chinese breast cancer patients. Breast Cancer Res Treat 2008;115:325-33. [CrossRef]

23. Zhang HM, Xuan LX, Gao JD, Zhang BN, Zhao P. Clinical characteristics comparison between triple-negative and non-triple-negative breast cancer. Zhonghua Wai Ke Za Zhi 2009;47:506-10.

24. He Q, Wang J, Shao YG, Zhou XY, Shao ZM. Clinical-pathological characteristics and survival of triple negative breast cancer. Zhonghua Yi Xue Za Zhi 2009;89:243-7 